NBER WORKING PAPER SERIES

\title{
THE SENSITIVITY OF LABOR DEMAND \\ FUNCTIONS TO CHOICE OF \\ DEPENDENT VARIABLE
}

George J. Borjas

Working Paper No. 1624

\author{
NATIONAL BUREAU OF ECONOMIC RESEARCH \\ 1050 Massachusetts Avenue \\ Cambridge, MA 02138 \\ June 1985
}

The research reported here is part of the NBER's research program in Labor Studies. Any opinions expressed are those of the author and not those of the National Bureau of Economic Research. 
NBER Working Paper 非 1624

June 1985

\author{
The Sensitivity of Labor Demand \\ Functions to Choice of \\ Dependent Variable
}

\begin{abstract}
This paper investigates whether the parameters of labor demand functions are sensitive to alternative methods of estimation. The assumption that the production technology is of the Generalized Leontief type implies that the demand system can be estimated by analyzing cross-section differences in earnings across labor markets, by studying longitudinal changes in earnings within a labor market, or by investigating cross-section differences in labor force participation rates across labor markets. The estimation of these models on the 1970 and 1980 Public Use Samples from the U.S. Census reveals that the estimates of labor demand functions are indeed quite robust to major specification changes.
\end{abstract}

George J. Borjas

Department of Economics University of California

Santa Barbara, CA 93106

(805) 961-2753 
The Sensitivity of Labor Demand Functions to Choice of Dependent Variable George J. Borjas*

\section{Introduction}

After a long period of relative neglect, the empirical study of labor demand functions has begun to attract the interest of labor economists.

Recent work by Berger (1983), Freeman (1979), Grant and Hamermesh (1981), and Johnson (1970), reveals the existence of substantively important interactions in the production process among various labor inputs. The earlier studies in this literature analyzed the substitution possibilities among labor inputs defined by skill level (e.g., blue and white collar work, high school and college graduates, etc.). However, major demographic shifts in the population (e.g., the continuing rise in the female participation rate, the fluctuation in the size of the youth cohort, and the increase in the number of immigrants) raise important policy questions about the impact of these demographic trends on labor markets. Hence more recent studies in the literature study the extent of substitution among labor inputs defined by race, sex, immigrant status, and/or other demographic traits. ${ }^{1}$ Even at this early stage, several major findings are emerging: (1) the increased participation rates of women has had a negative impact on male earnings (Berger, 1983; Freeman, 1979; and Grant and Hamermesh, 1981); (2) the increased entry of immigrants into the labor market did not have a major impact on the earnings of the native-born (Borjas, 1986; and Grossman, 1982); and (3) there is little evidence of a strong degree of substitution between blacks and Hispanics (Borjas, 1983). It is important to stress that all these findings are based on studies of 
cross-section data. In effect, the labor demand literature infers its conclusions by comparing labor markets (i.e., SMSAs) where certain demographic events occurred with labor markets where those events did not occur. For example, if the study found that men and women are strong substitutes in production, the data leading to this result is essentially a negative correlation across SMSAs between the earnings of men (women) and the relative number of women (men) in the labor force. Since differences exist across SMSAs in many other factors, the existence of these SMSA-specific fixed effects raises important questions about the robustness of cross-sectional findings.

This paper investigates whether the estimates of cross-section labor demand functions are sensitive to alternative methods of estimation. Two alternative methodologies will be presented. First, by pooling data from the 1970 and 1980 U.S. Censuses, the study will consider whether the technological relationships predicted by the cross-section results are similar to those obtained by a study of how changes in the earnings of particular groups in the 1970-1980 period are related to changes in the demographic characteristics of the labor market. The second test of the robustness of the cross-section results will investigate whether the observed labor force participation patterns are consistent with the predictions of the more traditional labor demand estimates (based on earnings or shares of earnings). The main finding of this paper is that the traditional cross-section results are indeed consistent with those obtained from alternative methods of estimation.

\section{Framework}

As sume that the production technology is characterized by the Generalized Leontief production function (Diewert, 1971) $:^{2}$ 


$$
\theta=\sum_{j} \sum_{i} \gamma_{i j}\left(x_{i} x_{j}\right)^{\frac{1}{2}},(i, j=1, \ldots, n)
$$

where $\theta$ is output; $X_{i}$ are the various inputs; and $\gamma_{i j}$ are the technology coefficients. The production function in (1) is linearly homogeneous and restricts the values of the technology parameters so that $\gamma_{i j}=\gamma_{j i}$. The sign of $\gamma_{i j}$ determines whether inputs $i$ and $j$ are substitutes $\left(\gamma_{i j}<0\right)$ or complements $\left(\gamma_{i j}>0\right) .^{3}$

The assumption that firms in this labor market maximize profits and face constant input prices leads to the marginal productivity conditions:

$$
w_{i}=\gamma_{i i}+\sum_{j \neq i} \gamma_{i j}\left(x_{j} / x_{i}\right)^{\frac{1}{2}}, i, j=1, \ldots, n,
$$

where $w_{i}$ is the price of input $i$. Equations (2) show the main advantage of the Generalized Leontief technology: linear-in-parameters wage equations.

Thus the Generalized Leontief technology can provide an important link between studies of wage determination and input demand theory.

Although the signs of the parameters $\gamma_{i j}$ contain information about the substitution possibility among the $n$ inputs, it is useful to transform these parameters into Hicks partial elasticities of complementarity (Hicks, 1970). This elasticity is defined by:

$$
c_{i j}=\frac{\theta \theta_{i j}}{\theta_{i} \theta_{j}}
$$

where $\theta_{i}=\partial \theta / \partial X_{i}, \theta_{i j}=\partial^{2} \theta / \partial x_{i} \partial X_{j}$. The Hicks elasticity of complementarity measures the effect on the relative price of factor $i$ of a change in the relative quantity of that factor, holding marginal cost and the quantities of other factors constant. In the Generalized Leontief technology, the elasticities of complementarity are given by: 


$$
c_{i j}= \begin{cases}\frac{\gamma_{i j}}{2\left(s_{i} s_{j} w_{i} w_{j}\right)^{\frac{1}{2}}}, & i \neq j . \\ \frac{\gamma_{i i}-w_{i}}{2 s_{i} w_{i}}, & i=j .\end{cases}
$$

where $s_{i}=w_{i} X_{i} / \theta$. The sign of $c_{i j}(i \neq j)$ depends on the cross-partial from the production function; it will be positive when the inputs are complements, and negative when the inputs are substitutes. Given this framework, the next three sections show how the parameters in (1) can be estimated from census data on earnings, earnings growth, and labor force participation.

\section{Cross-Section Earnings Analysis}

The cross-section estimation of the demand system in (2) is affected by two major econometric problems. First, equations (2) are not wage-determination functions unless (relative) supply conditions are also specified. It is not uncommon in the literature to estimate the production technology assuming that input supply is exogenous. The usual justification for this assumption is that the supplies of age-specific sex/race groups are fixed at a point in time. However, this assumption ignores the fact that although the total stock of the labor input may be treated as fixed, its distribution across labor markets is likely to be guided by input price differentials. Although initially the demand system will be estimated using ordinary least squares, the analysis below will also consider the impact of alternative estimation strategies (which account for the endogeneity of supply) on the empirical results.

The second econometric problem that has been ignored in the literature concerns the aggregation of workers into labor inputs $X_{i}$. An implicit assumption in specifying (1) is that all group $i$ workers are homogeneous within and across labor markets. Of course, there exist differences in the skill levels of individuals within each of these groups, and this may lead 
to group i individuals having different average skills across different labor markets. Hence wage differentials (or income share differences) across SMSAs may simply reflect an unequal distribution of skill levels. This problem can be approached by characterizing an individual's effective labor supply in terms of a fixed effect indexing the skill level of the individual. In particular, the wage paid to individual $\ell$ in group $i, w_{i \ell}$, depends on: (a) the marketdetermined wage level for the average group $i$ person, $w_{i}$; and (b) how the skills of individual 2 vary from the skills of the average group $i$ person, $f_{\ell}$. Hence $w_{i \ell}=w_{i \ell}\left(w_{i}, f_{\ell}\right)$, and the individual's wage rate depends both on market forces and on his (relative) skill level.

To make this approach useful it is necessary to add structure to the model. Two possible simplifications are $w_{i \ell}=w_{i} f_{\ell}$ and $w_{i \ell}=w_{i}+f_{\ell}$. The additive fixed effect assumes that the wage premium due to differential skills is independent of the demographic characteristics of the labor market, while the multiplicative specification allows for the possibility of such an interaction. ${ }^{4}$ Both of these models were used in preliminary work and the results were quite similar. For simplicity, the analysis in this paper uses the additive specification. If it is assumed that $f_{\ell}$ can be written in terms of both observable socioeconomic characteristics, $Z_{\ell}$, and a random uncorrelated error, $\varepsilon_{\ell}$, the stochastic equivalent of (2) is given by:

$$
w_{i \ell}=z_{\ell} \beta_{i}+\sum_{j \neq i} \gamma_{i j}\left(x_{j} / x_{i}\right)^{\frac{1}{2}}+\varepsilon_{\ell}, i, j=1, \ldots, n \text {. }
$$

Equation (5) shows how individual earnings are affected not only by socioeconomic characteristics, but also by the environment in which the individual is employed.

The data set used in the cross-section analysis is the 1980 A Sample from the U.S. Census. ${ }^{5}$ The study was restricted to working-age individuals ( $18 \leq$ age S64) who: (a) are not in the military; (b) are not self-employed; and (c) had records containing complete information on the variables used in the analysis. The "local labor market" is defined to be the SMSA where the individual resides. 
There was considerable experimentation in the determination of the number and definition of the labor inputs to be included in the production process. Most of the crucial results of the study can be obtained from a four-way breakdown of the labor input: white males (WM), black males (BM), immigrant males (IM), and females (F). Some of the results obtained under an alternative disaggregation of the labor force are discussed below.

The employment data necessary for the estimation of equations (5) are obtained from the Census files. The labor input $X_{i}$ (in the SMSA) is defined as the number of individuals in group $i$ who are of working age and were employed in 1979. Finally, the capital (K) data is drawn from Grant (1979). It gives the capital stock in each of 84 SMSAs for over a ten-year period up to 1969 , and was constructed from the Census of Manufactures and the Annual Survey of Manufactures. ${ }^{6}$ The capital data used below is the 1979 extrapolation made from the time-series. It is well known that capital stock calculations are subject to large measurement errors. To complicate matters, the capital data is available only for manufacturing industries. Since the analysis in this paper is conducted over all industries, the capital data leads to biased parameter estimates unless it is assumed that the aggregate capital stock in the SMSA is (roughly) proportional to the manufacturing capital stock.

Equation (5) was estimated on the micro Census data using 1979 annual earnings as the dependent variable. The use of annual earnings, instead of the wage rate, facilitates comparison between the results in this paper and those available in the labor demand literature which uses the average income share in a given year to estimate translog equations. 7 The variables held constant in the vector $Z$ include: years of schooling, years of labor market experience (age-schooling-6), and years of labor market experience squared. The estimated coefficients (using the restrictions $\gamma_{i j}=\gamma_{j i}$ ) obtained from the OLS regression are presented in Panel A of Table 1 . Several findings are 
worth noting. First, immigrant males are not substitutes with black males. In fact, these two inputs - under the assumption of exogenous relative supplies are complements. However, immigrant males do compete with white males in the labor market. Second, women and white men are strong substitutes in production. This result reinforces the emerging finding in the literature that the entry of women into the labor force has negatively affected the male labor market. Finally, capital and all the labor inputs (except for women) are strong complements in production. This result, again, is consistent with the thrust of the findings in the literature.

One important objection to these results is that the oLS estimation views (relative) labor supplies as perfectly inelastic. The wage differentials created across labor markets by the interactions among labor inputs are likely to induce internal migration patterns where the groups move to areas where they are likely to do relatively well. The presence of mobility costs and/or imperfect information suggests that the wage differentials do not vanish in the long run and that the correct estimation of (5) requires that the supply of inputs to labor markets be modeled more fully.

To account for the endogeneity of the supply variables, it is assumed that at the SMSA level relative supplies of labor inputs are affected by a vector of socioeconomic characteristics, A, describing the SMSA. Hence:

$$
\left(X_{j} / X_{i}\right)^{\frac{1}{2}}=A \beta+\varepsilon .
$$

The vector A includes the proportions of the labor force employed in each of the one-digit industrial groupings, the probability of receiving SSI assistance (relative to the poverty rate), and the mean level of SSI payments (relative to the mean wage level in the SMSA.) $)^{8}$ The industrial composition of the SMSA is likely to affect supplies since particular combinations of industrial concentrations will attract individuals with specific skills to the locality. 
Similarly, the chances of receiving a particular form of public assistance (SSI), relative to the SMSA's poverty rate, as well as the "real" levels of that assistance, measure the economic welfare of low income individuals in the SMSA. If the expected value of public assistance payments differs significantly across SMSAs, geographic differences in the location of racial and/ or immigrant groups are likely to arise.

The bottom panel of Table 1 presents the 2SLS estimates of the demand system. Note that controlling for the endogeneity of relative labor supplies does not alter the substantively important results of the analysis. For example, in both panels of Table 1 white men and women are substitutes in production, and immigrants have a negative impact on the earnings of white men but a positive impact on the earnings of black men. 9

Using the results in Table 1 , Hicks elasticities of complementarity were calculated and are presented in Table 2. With the exception of the own-elasticity for females (which is insignificantly different from zero), all the oLS ownelasticities are negative as predicted by the theory. ${ }^{10}$ Since $d \ln w_{i} / d \ln x_{j}$ $=s_{j} c_{i j}$ the estimated elasticities in Table 2 can be used to predict the behavior of wages as the supplies of the various groups in the labor force shift. 11 For example, using the oLS regression, a ten percent increase in the number of women in the labor force is predicted to lead to a .2 percent drop in the earnings of white men, while a ten percent increase in the number of male immigrants leads to only a .1 percent decrease in the white male wage. Thus even if white men and the female and immigrant inputs are indeed substitutes, the numerical impact of these groups on white male earnings is small.

\section{Time-Series Earnings Analysis}

Practically all that is known about the extent of labor substitution among different labor inputs is inferred from cross-section regressions similar 
to those presented in Table 1 (or their translog counterparts). One potential problem with this literature is that variation in earnings or income shares across labor markets may simply be representing the impact of unobserved fixed effects across SMSAs. One solution to this problem would be to study the behavior of earnings within the SMSA as (presumably exogenous) demographic shocks change the composition of the labor force. If a sufficiently large longitudinal data set was available within each SMSA, the estimation of equations like (5) in differenced form could yield the technology parameters from earnings growth regressions at the micro level. Since different censuses cannot be used to match individuals across data sets, the best alternative is to aggregate the data at the SMSA level, thus making the SMSA the unit of observation, and estimate the earnings growth regression:

$$
\Delta \bar{w}_{i}=\left(\Delta \bar{z}_{i}\right) \beta_{i}+\sum_{j \neq i} \gamma_{i j}\left[\Delta\left(\frac{X}{X_{i}}\right)^{\frac{1}{2}}\right]+v_{i}, \quad(i, j=1, \ldots, n),
$$

where $\Delta \bar{w}_{i}$ is the change in average annual earnings (in 1979 dollars) between 1979 and 1969 for group $i ; \Delta \bar{Z}_{i}$ is the change in the average values of the socioeconomic characteristics; and $\Delta\left(X_{j} / X_{i}\right)^{\frac{1}{2}}$ is the change in the relative employment variable.

Using the 1970 and 1980 Public Use Samples from the U.S. Census, and assuming that the change in the relative supplies of the labor inputs was exogenous, the top panel of Table 3 presents the OLS estimates of the production technology obtained from the estimation of equation (7). ${ }^{12}$ Three basic results are obtained. First, men and women are substitutes in production. Second, immigrant men and white men (but not black men) are substitutes in production. Third, capital and the various labor inputs are complements in production. It is important to stress that these three findings are essentially the three results given by the cross-section analysis in Table 1. Thus the estimation of the demand system using earnings growth 
data reveals the same substantive patterns as those given by the comparison of earnings across different SMSAs.

There is, however, one difference between the ols results in Table 1 and the "longitudinal" results in Table 3: the magnitude of the cross-section technology coefficients is usually smaller (in absolute value) than the magnitude of the same parameters in Table 3. Thus, although the use of cross-section data does not lead to different conclusions regarding the substitution possibilities among various labor inputs, it does lead to somewhat more inelastic responses than those given by the longitudinal data.

Of course, the longitudinal OLS results are even more sensitive to the criticism that it is unlikely that changes in relative supplies in the labor market over the 1970-1980 period are exogenous. To correct this problem, the first stage supply function in (6) is adapted to the longitudinal analysis by taking first differences at the SMSA level. This yields:

$$
\Delta\left(\frac{X^{j}}{X_{i}}\right)^{\frac{1}{2}}=(\Delta A) \beta+\varepsilon^{\prime},
$$

where $\Delta A$ is the difference in the value of the market aggregate variables. ${ }^{13}$ The 2SLS coefficients yielded by the longitudinal analysis are presented in the bottom panel of Table 3 . The most visible change in the coefficients made by the 2SLS technique is the relatively large rise in their standard errors. This change can be traced to the fact that the variables in the first stage regressions do not do a good job of explaining changes in relative supplies across SMSAs. While the $\mathrm{R}^{2}$ in the first-stage cross-section reduced form regressions often exceeded .5 , the $\mathrm{R}^{2}$ in the corresponding reduced form longitudinal regressions was usually below. 1 . This lack of predictive power led to substantial error in the instruments, and to the relatively insignificant coefficients in the second stage. Nevertheless, the signs of the technology parameters repeat the story familiar from the cross-section and longitudinal coefficients presented earlier. 


\section{Labor Force Participation Analysis}

The previous sections have shown how earnings data can be used to estimate the parameters of the production technology. An important advantage of the Generalized Leontief functional form is that the technology parameters can also be estimated by studying the determinants of the labor force participation decision. The participation decision for individual $\ell$ in group $i$ is based on a comparison of his market wage, $w_{i \ell}$, and his reservation wage, wil Define:

$$
I_{i \ell}=w_{i \ell}-w_{i \ell}^{*}
$$

The individual will participate in the labor force if $\mathrm{I}_{i \ell}>0$. Using (5) and assuming that the same vector of socioeconomic characteristics, $Z_{i 2}$, determines the reservation wage, equation (9) becomes:

$$
I_{i \ell}=z_{i \ell} \alpha+\sum_{j \neq i} \gamma_{i j}\left(x_{j} / x_{j}\right)^{\frac{1}{2}}+v_{i}
$$

where $v_{i}$ is a statistical residual. The vector $\alpha$ estimates the net impact of the socioeconomic variables on the participation decision. If the relative supplies of the labor inputs do not affect individual $l^{\prime} s$ reservation wage, the estimation of (10) identifies the technological parameters $\gamma_{i j}$.

Equations (10) were estimated using the linear probability model since the large sample sizes and the large numbers of variables and equations make maximum likelihood methods difficult to implement. This procedure also has the additional advantage that the cross-equation symmetry restrictions can be easily imposed. The OLS estimates of the technology coefficients are presented in the top panel of Table 4. The main result of the regression is that the analysis of labor force participation rates telis basically the same story as the earnings regressions. For instance, an increase in the number of male immigrants in the SMSA leads to lower participation rates for white men but to higher participation rates for black men. Since there is a positive correlation 
between participation rates and wages, the results imply a substitutability between white men and immigrants, and a complementarity between black men and immigrants. Secondly, in labor markets where women represent a large fraction of the labor force, both the participation rates of black men and white men fall significantly. Finally, in SMSAs where the relative capital stock is high, the participation rate of all the labor groups rises. In short, the qualitative extent of labor market substitution among the four labor inputs considered in this study is invariant to the choice of dependent variable in the demand function. Generally, if inputs $i$ and $j$ are found to be complements, the analysis in this paper reveals that as input $i$ enters the labor market the wage of the other input $j$ rises (relative to that obtained in other SMSAs), the participation rate of input $j$ rises, and the wage of input $j$ grows faster over time.

As in the previous sections, the assumption of exogeneity in relative supplies may impart a serious bias on the estimates of the labor force participation regressions. Using the aggregate supply functions in (6), the bottom panel of Table 4 presents the 2SLS coefficients estimated from the labor force participation model. A comparison of the two panels in Table 4 reveals only minor shifts in the coefficients. Thus the analysis of labor force participation propensities - within a labor demand framework - confirms the robustness of the substantive results implied by the earnings data.

\section{Disaggregation of Labor Inputs}

Finally, a serious problem with the empirical implementation of the labor demand model is that the theory provides no guidance as to how the labor force is to be disaggregated into the labor inputs $X_{i}$. This paper has used a four-way breakdown of the labor force to analyze the sensitivity of labor demand estimates. It is, therefore, important to determine whether the positive results of the previous sections hold up under alternative disaggrega- 
tions of the labor force. A substantively interesting experiment can be made by disaggregating the male immigrant sample into recent immigrants (immigrants who have been in the U.S. fewer than 10 years), and "older" immigrants (immigrants who have been the the U.S. longer than 10 years). This disaggregation, of course, is designed to account for the well known fact that more recent immigrants face different labor market experiences than earlier immigrants.

Table 5 presents selected technology coefficients from the labor demand systems estimated using earnings, earnings growth, and participation rates under this more detailed disaggregation. Consider the oLs coefficients for the three alternative dependent variables. These coefficients reveal that white men are substitutes with both types of immigrants, with the degree of substitutability being somewhat stronger for the older immigrant sample. In addition, black men are complements with both types of immigrants. These results are not only consistent with the findings from the earlier sections, but as Table 5 shows they are also invariant to the choice of dependent variable. The disaggregation of the immigrant group, therefore, confirms the main conclusion of this paper: estimates of labor demand functions are quite robust to major specification changes.

\section{Summa ry}

This paper has analyzed the sensitivity of labor demand functions to choice of dependent variables. It was shown that the use of a Generalized Leontief technology allows the parameters of the demand system to be estimated from data on earnings, earnings growth, or labor force participation rates. Remarkably, the analysis of 1970 and 1980 Census data indicated that the estimates of labor demand functions were invariant to model specification.

The empirical study led to three substantive findings: (1) there exists a strong degree of substitution between men and women in production; (2) male 
immigrants have not had a negative impact on the earnings of black men, but have had a small negative effect on the earnings of white native men; (3) capital and most labor inputs are complements in production.

The analysis showed that each of these three empirical facts was corroborated by the behavior of wage levels, wage growth during the 1970-1980 period, and labor force participation rates across labor markets. The robustness of labor demand functions, therefore, implies that a wide array of important empirical insights can be derived from continuing study of the substitutability of labor inputs in the marketplace. 


\section{Footnotes}

$*$

Professor of Economics, University of California, Santa Barbara, and Research Associate, National Bureau of Economic Research. This research was supported by grants from the Rockefeller Foundation and the Department of Health and Human Services.

1

See the survey by Hamermesh (1985) for a detailed description of the two phases in this literature.

2 The choice of the Generalized Leontief functional form over alternative production functions (such as the translog) is essentially arbitrary. Recent experiments by Griffin (1982) and Wales (1977) show that over certain ranges of the data the translog function provides a better fit while over other ranges the Generalized Leontief equation does a better job.

3 Another restriction implied by (1) is that diminishing marginal productivity for input $\ell$ requires that not all $\gamma_{\ell j}(j=1, \ldots, \ell-1, \ell+1, \ldots, n)$ be negative. For a discussion of this issue, and a related restriction on the signs of the elasticities of complementarity (whose sign depends directly on $\gamma_{\mathbf{i j}}$ ), see Diewert (1971) and Sato and Koizumi (1973).

Note that the definition of the fixed effect requires that $E\left(f_{\ell}\right)=1$ in the multiplicative specification, and $\mathrm{E}\left(\mathrm{f}_{\ell}\right)=0$ in the additive model.

5 Since the Census data is quite large random samples were drawn from the 5/100 A sample. The sampling proportions used are available from the author on request. The sample sizes satisfying all the selection criteria discussed in this section were 35804 white males, 4136 black males, 40459 male immigrants, and 62710 females.

6 The 84 SMSAs used by Grant (1979) to construct the capital time series are not a random sample of the 310 SMSAs identified in the A Sample of the 1980 Census since they tend to be the largest SMSAs in the country. 
7

The study was replicated using the wage rate as the dependent variable with similar qualitative results.

8 The industrial composition variables were calculated from the 1980 Census file while the public assistance variables were obtained from the 1976 Survey of Income and Education.

9

The OLS results do differ from the 2SLS results in one important way: the absolute value of the technology parameters tends to increase by 2 to 3 times in the 2SLS regressions. The meaning of this result is unclear since in the simpler two-equation suppply and demand model the differences in oLS and 2SLS coefficients depend on: (a) the correlation between the levels of the supply and demand functions; and (b) the relative variance of the two error terms. The more complex model estimated in this paper includes across-equation restrictions, thus further clouding the relationship between the statistical assumptions needed to generate the observed differences and the economic content of these assumptions.

10 The own-elasticities of complementarity were calculated by using the fact that $\sum_{j} s_{j} c_{i j}=0$.

11 The income shares are: $s_{W}=.422, s_{B}=.034, s_{I M}=.035, s_{F}=.197$, and $\mathrm{s}_{\mathrm{K}}=.312$.

12 Since differenced aggregate data is being used in the regression, the variance of the residuals is given by $\sigma^{2}\left(n_{0}+n_{1}\right) / n_{0} n_{1}$, where $n_{t}$ is the sample size in year $t(t=0,1)$. The regressions in Table 3 correct for the heteroscedasticity in the residual error.

13 Since the public assistance variables used in (6) are not available in Census data the change in these variables cannot be calculated. Hence equation (8) uses the two public assistance variables in level form. 
TABLE 1

TECHNOLOGY COEFFICIENTS FROM CROSS-SECTION EARNINGS REGRESSION *

PANEL A: OLS ESTIMATES

$\begin{array}{lcccc} & \text { BM } & \text { IM } & \text { F } & \text { K } \\ \text { WM } & -157.8 & -929.6 & -751.1 & 1542.9 \\ & (-.67) & (-7.25) & (-2.90) & (18.18) \\ \text { BM } & & 591.1 & 122.4 & 332.8 \\ & & (4.19) & (.54) & (4.19) \\ \text { IM } & & 895.4 & 285.4 \\ & & (6.43) & (8.88) \\ \text { F } & & & -213.7 \\ & & & (-4.39)\end{array}$

PANEL B : 2SLS ESTIMATES

$\begin{array}{lcccc} & \text { BM } & \text { IM } & \text { F } & \text { K } \\ \text { WM } & 1099.7 & -2049.5 & -2581.5 & 1408.4 \\ & (2.18) & (-8.67) & (-3.22) & (12.66) \\ \text { BM } & & 1099.7 & -337.0 & -785.7 \\ & & (2.18) & (-1.30) & (-1.36) \\ \text { IM } & & 2099.4 & 416.4 \\ & & & (7.93) & (9.74) \\ \text { F } & & & -85.8 \\ & & & & (-1.29)\end{array}$

* The t-ratios are given in parentheses. 
TABLE 2

ELASTICITIES OF COMPLEMENTARITY FROM EARNINGS REGRESSION *

PANEL A: OLS ESTIMATES

\begin{tabular}{|c|c|c|c|c|c|}
\hline & WM & $\mathrm{BM}$ & IM & F & K \\
\hline WM & $\begin{array}{l}-3.021 \\
(-2.25)\end{array}$ & $\begin{array}{l}-.041 \\
(-.67)\end{array}$ & $\begin{array}{c}-.223 \\
(-7.25)\end{array}$ & $\begin{array}{c}-.099 \\
(-2.90)\end{array}$ & $\begin{array}{c}4.178 \\
(18.18)\end{array}$ \\
\hline $\mathrm{BM}$ & & $\begin{array}{r}-34.320 \\
(-6.32)\end{array}$ & $\begin{array}{c}.582 \\
(4.19)\end{array}$ & $\begin{array}{l}.062 \\
(.54)\end{array}$ & $\begin{array}{r}3.691 \\
(4.19)\end{array}$ \\
\hline IM & & & $\begin{array}{r}-26.245 \\
(-2.44)\end{array}$ & $\begin{array}{c}.444 \\
(6.43)\end{array}$ & $\begin{array}{l}2.902 \\
(8.88)\end{array}$ \\
\hline $\mathrm{F}$ & & & & $\begin{array}{c}1.274 \\
(.67)\end{array}$ & $\begin{array}{l}-1.197 \\
(-4.39)\end{array}$ \\
\hline & & & & & -5.623 \\
\hline
\end{tabular}

PANEL B: 2SLS ESTIMATES

$\begin{array}{lccccc} & \text { WM } & \text { BM } & \text { IM } & \text { F } & \text { K } \\ \text { WM } & & & & & \\ & (-2.644 & .288 & -.491 & -.340 & 3.814 \\ \text { BM } & (2.18) & (-8.67) & (-3.22) & (12.66) \\ & & 76.256 & 1.083 & -.171 & -8.713 \\ \text { IM } & (1.01) & (2.18) & (-1.30) & (-1.36) \\ & & & -38.729 & 1.040 & 4.234 \\ \text { F } & & (-2.30) & (7.93) & (9.74) \\ & & & & 1.335 & -.481 \\ \text { K } & & & (.34) & (-1.29) \\ & & & & & -4.380\end{array}$

* The t-ratios refer to the parameter $\gamma_{i j}$ in the cross-elasticity estimates, and to $\left(\gamma_{i i}-w_{i}\right)$ in the own-elasticity estimates. No standard error is available for the own-elasticity of capital since a capital equation was not estimated and hence the value of $\gamma_{i i}{ }^{-w_{i}}$ cannot be predicted from a regression equation. 
TABLE 3

TECHNOLOGY COEFFICIENTS FROM EARNINGS GROWTH REGRESSIONS *

PANEL A: OLS ESTIMATES

$\begin{array}{lcccc} & \text { BM } & \text { IM } & \text { F } & \text { K } \\ \text { WM } & -1569.7 & -2725.5 & -1961.8 & 2702.8 \\ & (-8.2) & (-2.60) & (-2.01) & (2.69) \\ \text { BM } & & 673.5 & -3619.0 & 2325.5 \\ & & (.33) & (-2.85) & (1.79) \\ & & & -197.2 & 1396.5 \\ \text { IM } & & & (-.17) & (1.68) \\ & & & & 1415.6 \\ \text { F } & & & & (2.06)\end{array}$

PANEL B: 2SLS ESTIMATES

$\begin{array}{lcccc} & \text { BM } & \text { IM } & \text { F } & \text { K } \\ \text { WM } & -7548.9 & -4577.6 & -3631.1 & 7394.5 \\ & (-1.75) & (-2.25) & (-1.71) & (2.44) \\ \text { BM } & & 2264.9 & -999.2 & 3852.3 \\ & & (.68) & (-.43) & (-1.27) \\ \text { IM } & & & & \\ & & & (1.00) & (.43) \\ & & & & 320.4 \\ \text { F } & & & & (.19)\end{array}$

* The $t$-ratios are given in parentheses. 
TABLE 4

TECHNOLOGY COEFFICIENTS FROM LABOR FORCE PARTICIPATION REGRESSIONS *

PANEL A: OLS ESTIMATES

$\begin{array}{ccccc} & \text { BM } & \text { IM } & \text { F } & \text { K } \\ \text { WM } & .0690 & -.0095 & -.1582 & .0187 \\ & (7.84) & (-2.47) & (-15.59) & (6.98) \\ \text { BM } & & & & \\ & & (5.0201 & -.0885 & .0018 \\ & & (-9.66) & (.63) \\ \text { IM } & & -.0172 & .0063 \\ & & & (-3.88) & (7.50) \\ \text { F } & & & .0034 \\ & & & & (1.58)\end{array}$

PANEL B: 2SLS ESTIMATES

$\begin{array}{llccc} & \text { BM } & \text { IM } & \text { F } & \text { K } \\ \text { WM } & .0779 & .0083 & -.1972 & .0254 \\ & (4.00) & (.97) & (-6.51) & (7.17) \\ \text { BM } & & & & \\ & & .0418 & -.1073 & .0019 \\ & & (5.05) & (-4.65) & (.55) \\ \text { IM } & & -.0435 & .0088 \\ & & & (-4.33) & (7.65) \\ \text { F } & & & .0050 \\ & & & & (1.67)\end{array}$

* The $t$-ratios are given in parentheses. 
TABLE 5

TECHNOLOGY COEFFICIENTS USING DISAGGREGATED IMMIGRANT SAMPLE *

\begin{tabular}{|c|c|c|c|c|}
\hline DEPENDENT & \multicolumn{2}{|c|}{ White Men } & \multicolumn{2}{|c|}{ Black Men } \\
\hline $\begin{array}{l}\text { VARIABLE/ } \\
\text { Methodology }\end{array}$ & $\begin{array}{c}\text { Recent } \\
\text { Immigrants }\end{array}$ & $\begin{array}{c}\text { Earlier } \\
\text { Immigrants }\end{array}$ & $\begin{array}{l}\text { Recent } \\
\text { Immigrants }\end{array}$ & $\begin{array}{c}\text { Earlier } \\
\text { Immigrants }\end{array}$ \\
\hline$w$, OLS & $\begin{array}{l}-160.5 \\
(-1.05)\end{array}$ & $\begin{array}{r}-1342.3 \\
(-7.28)\end{array}$ & $\begin{array}{l}291.7 \\
(1.99)\end{array}$ & $\begin{array}{l}348.8 \\
(1.83)\end{array}$ \\
\hline$w, 2 S L S$ & $\begin{array}{l}-801.0 \\
(-2.06)\end{array}$ & $\begin{array}{r}-2215.8 \\
(-4.85)\end{array}$ & $\begin{array}{l}-420.3 \\
(-1.23)\end{array}$ & $\begin{array}{r}239.2 \\
(.56)\end{array}$ \\
\hline$\Delta w$, OLS & $\begin{array}{r}-1469.1 \\
(-1.26)\end{array}$ & $\begin{array}{r}-1777.8 \\
(-1.77)\end{array}$ & $\begin{array}{r}741.6 \\
(.36)\end{array}$ & $\begin{array}{r}202.6 \\
(.10)\end{array}$ \\
\hline$\Delta \mathrm{w}, 2 \mathrm{SLS}$ & $\begin{array}{r}-3799.6 \\
(-1.59)\end{array}$ & $\begin{array}{r}-2646.5 \\
(-1.09)\end{array}$ & $\begin{array}{r}1601.6 \\
(.47)\end{array}$ & $\begin{array}{r}313.7 \\
(.09)\end{array}$ \\
\hline LFP, OLS & $\begin{array}{r}-.0005 \\
(-.14)\end{array}$ & $\begin{array}{l}-.0118 \\
(-2.73)\end{array}$ & $\begin{array}{l}.0109 \\
(2.85)\end{array}$ & $\begin{array}{l}.0111 \\
(2.54)\end{array}$ \\
\hline LFP, 2SLS & $\begin{array}{l}-.0179 \\
(-1.50)\end{array}$ & $\begin{array}{l}.0273 \\
(2.16)\end{array}$ & $\begin{array}{r}-.0013 \\
(-.14)\end{array}$ & $\begin{array}{l}.0601 \\
(5.20)\end{array}$ \\
\hline
\end{tabular}




\section{Bibliography}

Berger, Mark C., "Changes in Labor Force Composition and Male Earnings: A Production Approach," Journal of Human Resources 18 (Spring 1983), $177-196$.

Borjas, George J., "The Substitutability of Black, Hispanic and White Labor," Economic Inquiry 21 (January 1983), 93-106.

, "The Demographic Determinants of the Demand for Black Labor," in The Black Youth Unemployment Crisis, edited by Richard B. Freeman and Harry J. Holzer. Chicago: University of Chicago Press, 1986.

Diewert, W.E., "An Application of the Shephard Duality Theorem: A Generalized Leontief Production Function," Journal of Political Economy 79 (May/June 1971), 481-507.

Freeman, Richard B., "The Effect of Demographic Factors on Age-Earnings Profiles," Journal of Human Resources 14 (Summer 1979), 289-318.

Grant, James H., "Substitution Among Labor, Labor and Capital in U.S. Manufacturing," Ph.B. diss., Michigan State University, 1979.

and Hamermesh, Daniel S, "Labor Market Competition Among Youths, White Women and Others," Review of Economics and Statistics 63 (August 1981), 354-360. 
Griffin, James M., "The Approximation Characteristics of Generalized Functional Forms: Results from Pseudo-Data Experiments," Advances in Applied Microeconomics $2(1982), 3-18$.

Grossman, Jean B., "The Substitutability of Natives and Immigrants in Production," Review of Economics and Statistics 64 (November 1983), 596-603.

Hamermesh, Daniel S., "Labor Substitution, Unemployment and Wages - With Reference to Youths and Women," Mimeograph, Michigan State University, 1984.

, "The Demand for Labor in the Long Run," in Handbook of Labor Economics, edited by 0 . Ashenfelter and R. Layard. New York: North-Holland Press, 1985.

Hicks, John., "Elasticity of Substitution Again: Substitutes and Complements," Oxford Economic Papers 22 (November 1970), 289-296.

Johnson, George., "The Demand for Labor by Educational Category," Southern Economic Journal 37 (October, 1970), 190-204.

Sato, Ryuzo and Koizumi, Tetsunori., "On the Elasticities of Substitution and Complementarity," Oxford Economic Papers 25 (March 1973), 44-56.

Wales, Terence J., "On the Flexibility of Functional Forms: An Empirical Approach," Journal of Econometrics 20 (June 1977), 183-193. 